\title{
FUNDAMENTACIÓN DE LOS DERECHOS DE PROPIEDAD: CLÁSICOS Y MODERNOS
}

Michel Zouboulakis*

$\mathrm{E}^{1}$ tema económico más álgido desde el décimo mandamiento (“No codiciarás los bienes ajenos”) es, quizá, “¿quién posee qué”? En nuestro sistema socioeconómico, toda discusión sobre el proceso de producción capitalista trata inevitablemente de ese tema. Toda reflexión sobre la distribución y la desigualdad del ingreso parte de una definición aproximada de los derechos de los individuos sobre los resultados de su trabajo y de los medios de producción que poseen. Todo debate sobre el papel y los límites de la intervención del gobierno supone una definición más o menos clara de qué es propiedad privada y qué es propiedad pública. Es entonces muy ingenuo creer que los grandes pensadores económicos - como Adam Smith, David Ricardo, Nassau Senior y John Stuart Mill- nada importante tenían que decir sobre el tema. Pero si se leen los textos esenciales de los economistas neoclásicos que formularon el nuevo concepto de derechos de propiedad (DP) en los años sesenta, no hay ninguna referencia a la obra de sus antecesores clásicos ${ }^{1}$. ¡Como si ninguno de ellos jamás hubiese pensado en la propiedad y en el derecho a intercambiar el producto de su trabajo, su tierra o su capital!

* Doctor en Economía, jefe del Departamento de Economía, Universidad de Tesalia, Grecia, [mzoub@uth.gr]. Fecha de recepción: 11 de marzo de 2016, fecha de aceptación: 12 de mayo de 2016. Traducción de Alberto Supelano. Sugerencia de citación: Zouboulakis, M. S. "Fundamentación de los derechos de propiedad: clásicos y modernos", Revista de Economía Institucional 18, 34, 2016, pp. 13-28. DOI: http://dx.doi.org/10.18601/01245996.v18n34.02

${ }^{1}$ Ver Alchian (1959), Coase (1960), Demsetz $(1966 ; 1967)$ y Alchian y Demsetz (1972; 1973). En un trabajo más reciente, Demsetz alude a las ideas de Smith, Ricardo y Malthus sobre las causas del progreso económico para concluir que "los economistas clásicos no parecen haber elaborado un tratamiento verdaderamente sistemático y exhaustivo del problema del desarrollo económico" (2000, 70). Esto quizá explique por qué el análisis moderno de los DP omite los aportes clásicos al tema. 
E1 principal objetivo de este artículo es demostrar que los economistas políticos clásicos tenían profundas ideas sobre los derechos de propiedad y mostrar su significado para el debate actual. En la primera sección se exponen concisamente los principales conceptos teóricos del enfoque de los derechos de propiedad. En la segunda sección se presentan las ideas de la economía política clásica sobre el derecho a poseer y usar el trabajo, la tierra y el capital y su producto. En la última sección se comparan el enfoque clásico y el de derechos de propiedad.

\section{EL ENFOQUE MODERNO}

A comienzos de los años sesenta, algunos economistas de las universidades de Chicago, de California y de otros lugares intentaron responder algunas preguntas pendientes sobre las externalidades y el uso de recursos comunes. En el sistema capitalista, donde los medios de producción y los recursos son principalmente de propiedad privada, el intercambio de bienes y servicios consiste en un intercambio de "dos conjuntos de derechos de propiedad" (Demsetz, 1967, 347). En competencia perfecta, todos los recursos se asignan perfectamente a los individuos que buscan maximizar su beneficio personal (utilidad o ganancia) y tienen los incentivos adecuados. Esta asignación es eficiente cuando cada parte de la transacción paga el costo de lo que produce y recibe los beneficios correspondientes. Pero en el mundo real, muchos de esos costos y beneficios son externos a la persona que posee los recursos que utiliza. Y muchos derechos de propiedad no se pueden asignar porque se refieren a bienes comunes (lagos, ríos, costas, etc.) o porque es demasiado costoso asignarlos a través del mercado (Furubotn y Richter, 1998, 81). Por ello, la asignación de recursos está lejos de ser eficiente en presencia de externalidades y costos de transacción positivos.

El mérito por resolver este asunto pertenece a Coase (1960) y a los miembros de la escuela de DP que sugirieron una manera de internalizar las externalidades y los costos de transacción definiendo en forma clara y eficiente los derechos de propiedad involucrados; donde eficiente es un arreglo social que "corrige los defectos de una parte del sistema sin causar daños más graves en otras partes" (Coase, $1960,34)^{2}$. Como ya se dijo, los derechos de propiedad están en el centro del sistema capitalista y su papel siempre ha sido distribuir los recursos productivos poseídos privadamente mediante mecanismos

\footnotetext{
${ }^{2}$ El enfoque de DP no aborda los aspectos éticos de la distribución de los derechos y simplemente los da por sentado. Esta cuestión se examina en Randall (1978).
} 
de mercado. La estructura de DP puede diferir entre una sociedad y otra debido a su trayectoria histórica peculiar. Existen sociedades donde la mayoría de los recursos son de propiedad privada (Estados Unidos, Reino Unido); en otras, gran parte es de propiedad pública (Europa oriental y septentrional). Después de 1989 no hay sociedades donde la mayoría de los recursos pertenezcan al Estado, salvo tres excepciones. Aunque la estructura exacta de DP en cada sociedad tiene un desarrollo peculiar por razones históricas, la tipología de DP es en todas partes más o menos equivalente:

a. Asociados a objetos físicos o tangibles (tierras, casas, capital fijo, etc.).

b. Asociados a derechos intangibles o contractuales (activos, patentes, derechos de autor, etc.).

c. No cubiertos por la ley, derivados de relaciones sociales informales en el sentido de relaciones con clientes y amistades (Furubotn y Richter, 1998, 86).

Además, todas las relaciones de DP tienen una característica común: su carácter social. Los DP se refieren a relaciones entre personas y no a relaciones entre personas y cosas, de modo que aunque los DP provienen de la existencia de cosas, su uso depende del tipo de relaciones sociales (Furubotn y Pejovich, 1972). Esta característica es esencial, bien se trate de derechos "absolutos" o in rem dirigidos hacia cualquier otra persona, o de derechos "relativos" o in personam dirigidos hacia una o más personas determinadas por medio de contratos u órdenes judiciales (Merrill y Smith, 2001). En todos los casos, "la esencia del derecho de propiedad de un recurso es la aceptación de ese derecho por otros" (Hodgson, 2001, 250).

La relación entre propiedad y posesión o el derecho a disfrutar de un bien no es clara en la literatura de DP (ver Demsetz, 1966; Alchian, 1987; Barzel, 1989). No basta poseer o controlar un bien o un recurso; para excluir la propiedad del ladrón, los DP deben además ser protegidos por la ley. Como se señaló recientemente, un derecho de propiedad no es el resultado de una institución espontánea sino un derecho legítimo que la ley obliga a cumplir (Hodgson, 2015). Donde "legítimo" significa que es esencial el carácter de propiedad legal (Holcombe, 2014, 474; Williamson, 1985, 27). Ante todo, un DP no puede existir ni se puede garantizar sin la exigencia legal de una estructura permanente de toma de decisiones políticas (North, 1990, 48). El carácter de la estructura política (despótico, autocrático o democrático) es de gran importancia, pues está ligado directamente a la estructura de los intereses económicos involucrados. Como se ha 
observado, "los derechos de propiedad particulares son lo que son debido a quienes usan el gobierno para proteger sus intereses" (Samuels, 1999, 185). Al fin de cuentas, el carácter del control político afecta la eficiencia de los DP (Shleifer, 1995).

\section{EL ENFOQUE CLÁSICO}

La historia de los DP se remonta a las ciudades de la antigua Grecia, donde la protección legal de los derechos individuales era una característica constitucional de la organización del Estado (Ackroyd, 1992). En la era moderna, Thomas Hobbes fue el primero en subrayar el papel del Soberano para garantizar la paz y la defensa de sus súbditos, incluida su propiedad (1839, cap. XVIII). Pero se debe empezar por el Segundo tratado del gobierno de John Locke (1784) para encontrar una definición sustancial de DP cercana al enfoque clásico. Locke definió los derechos naturales de los hombres a tener propiedades, incluidas "sus vidas, libertades y haciendas" (ver Gordon, 1991, 81), entre ellos: a) el derecho al uso irrestricto de objetos físicos y de su poder productivo, b) el derecho de apropiarse el ingreso de esos objetos y el c) el derecho de transferir libremente su propiedad. El principal argumento de Locke para la propiedad privada es puramente individualista: los recursos productivos se pueden usar más eficientemente en privado que cuando se mantienen en común. Unos cincuenta años después, David Hume (1969) justificó el origen de los derechos individuales de propiedad con una adición esencial, la idea de escasez: la naturaleza ha "cargado" al hombre con "innumerables deseos y necesidades [...] y con medios escasos que le permiten aliviar esas necesidades" (1969, libro III, parte ii, secc. ii). Contra Locke, Hume rechazó todo argumento teleológico para explicar la aparición de los DP en favor de un argumento empírico: la propiedad surge a partir de las normas de justicia y las convenciones sociales de un tiempo y lugar (Young, $2008,56)^{3}$.

Siguiendo a Hume, Adam Smith construyó su propia teoría de los derechos de propiedad y sentó los fundamentos del enfoque clásico. Dedicó sus Lecturas sobre jurisprudencia al análisis filosófico de los derechos de propiedad y a la historia de su creación en sociedades civiles:

El primer y principal designio de todo sistema de gobierno es mantener la justicia; evitar que los miembros de la sociedad invadan la propiedad de otro, o se apoderen de lo que no es suyo. Aquí el designio es dar a cada uno la posesión segura y pacífica de su propiedad $(1982,54)$.

${ }^{3}$ Becker (1977) hace un detallado análisis filosófico del tema de los DP. 
Smith analiza los diferentes tipos de derechos "reales" (in rem) y "personales" para determinar los deberes del gobierno con sus ciudadanos. También examina cinco maneras de adquirir propiedad: por ocupación, por tradición, por adhesión, por prescripción y por sucesión (ibíd., 61). Su objetivo era trazar la evolución histórica de la propiedad, no solo de la tierra y los edificios sino de todo bien "móvil" susceptible de apropiación, desde el ganado y los minerales hasta las pinturas e invenciones técnicas. De modo que estaba bien preparado para iniciar, en La riqueza de las naciones, el análisis de la economía como un sistema autorregulado en un marco social históricamente determinado de costumbres, leyes y derechos de propiedad ${ }^{4}$. La esencia del nuevo sistema económico reside en la condición de que "los sagrados derechos de la propiedad privada" son protegidos por la ley y permitidos por la libertad (1976, I, 190).

\section{Trabajo}

Una doctrina esencial de la economía política clásica es que el trabajo es lo primero. De acuerdo con Locke, se creía firmemente que el valor de una cosa se debe principalmente al trabajo dedicado a producirla. Adam Smith mencionó el trabajo en la primera frase de la introducción a su tratado económico al señalar que "el trabajo anual de cada nación proporciona todo lo que consume anualmente" (ibíd., 1). También conectó directamente el trabajo y los derechos de propiedad: "la propiedad que cada hombre tiene de su propio trabajo, que es el fundamento original de todas las demás propiedades, es la más sagrada e inviolable" (ibíd., I, 136). Smith creía que el trabajo es el factor productivo más importante en la supervivencia humana. Por esa razón, el trabajo es el creador de riqueza que da origen a la propiedad (ver Milonakis y Fine, 2009, 50-51). En términos más concisos: no hay propiedad sin trabajo.

David Ricardo avanzó un paso más en la teoría del valor trabajo cuando intentó superar las inconsistencias de Smith con respecto a la medida del valor en términos de trabajo. Ricardo excluyó la escasez como fuente importante de valor y criticó a Smith por haber confundido el valor del trabajo con los salarios, es decir, con la cantidad de trabajo que se compra vendiéndolo. Para Ricardo, "el valor de una mercancía, o la cantidad de cualquier otra mercancía por la que se intercambia, depende de la cantidad relativa de trabajo necesario para

${ }^{4} \mathrm{E} 1$ concepto de derechos de propiedad resurgió en el siglo XX, en la obra de J. R. Commons, con el mismo espíritu de "vínculo económico que une a los individuos, como las transacciones, las deudas y los derechos de propiedad" (Commons, 1934, 33). 
su producción, y no de la mayor o menor remuneración que se paga por ese trabajo" $(1821,11)$. Como se sabe, no se encontró una medida coherente del valor en términos de la cantidad de trabajo incorporado hasta la mercancía patrón de Sraffa en 1960. Pero la idea de que el valor de todas las cosas proviene del trabajo, y que por ello solo el trabajador debía apropiárselo, sobrevivió y floreció en los escritos del adversario más eminente de los clásicos: Karl Marx.

Nassau William Senior fue el primer economista clásico que se apartó de la teoría del valor trabajo y la propiedad. Entre los "constituyentes de riqueza" incluyó la utilidad objetiva (el valor de uso), la escasez y la "transferibilidad", es decir, la capacidad de "ser transferido absolutamente o durante un periodo" $(1836,8)$. Senior fue muy consciente de definir la capacidad de transferir bienes y servicios mediante el atributo de la apropiación. No se pueden apropiar recursos físicos como los ríos y el mar. Análogamente, cualidades humanas como "la salud, la fortaleza y el conocimiento" solo son "transferibles imperfectamente" porque su poder productivo solo se contrata durante cierto periodo o en cierto grado (1836, 9-10). Por ello, Senior declaró que "la limitación de la oferta es de lejos la causa más importante" del valor, y criticó a sus colegas por haber exagerado la importancia del trabajo $(1836,24)$. Hablando de la distribución de la riqueza entre las "diferentes clases de la comunidad que tienen derecho a las cosas que se producen", hizo énfasis en los fundamentos legales del proceso de apropiación. Describió el papel del gobierno como protector de la riqueza de cada productor "contra la violencia o el fraude" a cambio de "cargas públicas" que los productores pagan al gobierno (1836, 87-88). En ese sentido, un impuesto directo es el costo de ejercer el derecho a usar un "instrumento de producción".

John Stuart Mill fue quien dio la definición clásica integral de los derechos de propiedad:

La institución de la propiedad [...] consiste en el reconocimiento, a cada persona, del derecho a disponer exclusivamente de lo que ha producido con su propio esfuerzo o recibido de quienes lo producen por donación o convenio justo, sin fuerza ni fraude $(1973,218)$.

El acento aún se mantiene en el lado productivo de la apropiación de bienes, aunque no exclusivamente. Mill no se limita a los propietarios de los tres factores de producción: tierra, capital y trabajo. Reconoce los "derechos de propiedad de los individuos sobre cosas que no han producido" (ibíd., cursivas nuestras). Además de los capitalistas que suministran fondos, materiales y maquinaria, incluye a quienes heredan propiedades y a quienes adquieren propiedad por libre consen- 
timiento: "El derecho de propiedad incluye entonces la libertad de adquirir mediante contrato" (ibíd., 220). Mill elude el problema del valor y de su medida para adoptar una teoría pragmática del valor basada en el costo de producción, en la que la combinación de trabajo y capital crea valor y riqueza. Su remuneración depende de la cantidad de trabajo y de capital que "se precisa para la producción" (ibíd., 480). Así se originó la propiedad privada, como fruto del trabajo y la abstinencia. En su Utilitarismo justificará además la propiedad en términos de justicia: "se considera muy injusto privar a alguien de su libertad personal, de su propiedad o de cualquier otro objeto que le pertenezca legalmente" (Mill, 1861, 241).

\section{CAPital}

Bien se sabe que los economistas clásicos consideraron que el capital junto con el trabajo era uno de los factores de producción fundamentales; a costa de la tierra, para minimizar el papel de los terratenientes en el proceso productivo y, por tanto, de sus pretensiones sobre parte del excedente. Entendían el capital como un resultado de la acumulación previa, es decir, como consecuencia del ahorro y la frugalidad. Adam Smith definió el capital como parte del acervo empleado productivamente para aumentar el producto anual de un país, a diferencia del "ingreso" que se gasta en usos improductivos (sirvientes, gasto militar, servicios públicos, etc.). Cuanto mayor sea la cantidad invertida en usos productivos, mayor será el producto anual. Por tanto, "los capitales aumentan por la parsimonia, y se reducen por la prodigalidad y la mala conducta" (1976, I, 358). Smith creía que el crecimiento económico anual solo es posible "por medio de capital adicional", puesto que el número de trabajadores productivos y el incremento de la maquinaria dependen de la abundancia de capital (ibíd., 364). Vinculando el crecimiento y la prosperidad con la acumulación de capital, subrayó que la condición necesaria para ella es la seguridad de los derechos de propiedad (Aspromourgos, 2009, 207). En su investigación histórica, Smith concluyó que "este esfuerzo, protegido por la ley y permitido por la libertad para actuar de la manera más ventajosa, es el que ha mantenido el avance de Inglaterra hacia la opulencia y el mejoramiento" (ibíd., 367, cursivas propias).

Ricardo adoptó una definición más amplia del capital, "aquella parte de la riqueza de un país que se emplea en la producción, la cual incluye los alimentos, el vestuario, las herramientas, las materias primas, la maquinaria, etc. necesarios para llevar a efecto el trabajo" $(1821,95)$. Lo importante aquí es el carácter subordinado del capital 
como auxiliar del factor productivo más creativo: el trabajo. Esto es en parte resultado de una idea más antigua del capital, de "avances" para la producción anual, una idea heredada de Quesnay y de la escuela fisiocrática. Los clásicos dieron un paso adelante distinguiendo entre capital fijo y circulante. Ricardo prestó especial atención al capital fijo, no solo porque era causa de una importante desviación de su idea del valor basada en la cantidad de trabajo, sino también porque era la base de su teoría de la distribución de las ganancias. Los capitalistas tienen el derecho legítimo de compartir el excedente solo porque avanzan su capital durante cierto periodo de tiempo. E1 "rasgo de genio" de Ricardo, dijo Schumpeter, fue ver en todo tipo de producción: agrícola, fabril o textil, "el mismo elemento fundamental, a saber, el lapso de tiempo entre la inversión y la aparición del bien de consumo correspondiente" $(1954,636)$. Cuando la cantidad de capital invertido se incrementa, su valor no siempre aumenta. Todo depende del valor de los componentes del capital avanzado: el valor de los alimentos, del vestuario, de las herramientas y materias primas varía de acuerdo con el precio de mercado de esos bienes. Eso afecta directamente el poder de compra de los salarios. En cambio, el valor del capital depende de la "durabilidad del capital empleado" o de la tasa de rotación $(1821,34)$. Cuanto mayor es el tiempo necesario para obtener el producto final, mayor será la ganancia. Sin embargo, la causa de las fluctuaciones permanentes de la tasa de ganancia depende de la distribución entre trabajadores, terratenientes y capitalistas. En últimas es un resultado del arreglo social entre las clases poseedoras de diferentes derechos de propiedad.

Senior revivirá la idea del capital como resultado de la parsimonia y la frugalidad, pero añadirá el nuevo concepto de "abstinencia", un término que expresa "la conducta de una persona que se abstiene del uso improductivo de lo que puede comandar o que prefiere intencionalmente la producción remota a la de resultados inmediatos" (1836, 58). En otras palabras, la abstinencia incluye el ahorro y la espera, y se presenta como un agente de producción independiente "distinto del trabajo y de la agencia de la naturaleza" (ibíd., 59). Senior hizo mucho énfasis en la psicología de la creación de capital para identificar a la persona que posee el derecho a compartir parte del producto: "La persona que así actúa [que se abstiene del uso improductivo de la riqueza] es un capitalista y la recompensa de su comportamiento es la ganancia" $(1836,89)$. En opinión de Senior la acumulación de capital es un factor esencial que aumenta la productividad de la tierra y del trabajo, y es así la fuente de un crecimiento incesante. 
Esa misma idea fue expresada lacónicamente por J. S. Mill: "1a industria está limitada por el capital” (1973, 63). Aunque Senior y Mill creían erróneamente que con el aumento del capital la tierra y el trabajo podían producir más "sin un límite asignable" (ibíd., 66), la idea de rendimientos crecientes del capital (heredada de John Rae) era verdadera y esencial. Atormentados por la profecía ricardiana de la tasa decreciente de ganancia, sus seguidores querían encontrar los medios para posponer sus efectos fortaleciendo el "deseo de acumulación”. Mill era mucho más consciente del hecho de que la fuerza de ese deseo no solo se relacionaba con el "carácter individual, sino con el estado general de la sociedad y la civilización” (ibíd., 165). Por ello insistió en estudiar las condiciones sociales que actúan como "causas de la diversidad en la fuerza efectiva del deseo de acumulación”. Usando algunas observaciones antropológicas rudimentarias de su época concluyó que la acumulación era mucho más fuerte en los "países más prósperos de Europa" porque prevalecen "la seguridad, la razón y el cálculo sobrio". Sacrificar los intereses inmediatos "en aras del bien futuro" no es solo un atributo moral del inversionista individual sino ante todo el resultado de "las mejores instituciones políticas del país, que por el alcance que han dado a la libertad de acción individual, han promovido la actividad personal y la confianza en sí mismo, mientras que por la libertad de asociación y combinación que confieren, facilitan la empresa industrial a gran escala" (ibíd., 174). En otras palabras, las razones de la "abundancia de los pródigos" se basan en la distribución apropiada de los DP.

\section{TIERRA Y RECURSOS NATURALES}

Como ya se dijo, los economistas políticos clásicos consideraban que la tierra era un factor de producción inevitable que se imponía como consecuencia de la distribución existente de derechos de propiedad de la tierra. "Por sucesión o por enajenación", escribió Adam Smith $(1976,407)$ la tierra se dividió en parcelas más pequeñas y se convirtió en propiedad privada garantizada por las leyes del país. A diferencia del trabajo y del capital, cuya prosperidad depende totalmente de las habilidades de su propietario, esta se basa "en el más absurdo de los supuesto [...] que la propiedad de la generación actual debe ser restringida y regulada por el capricho de quienes murieron hace quizá quinientos años" (ibíd., 409). La renta es "el precio que se paga por el uso de tierra" aunque no produzca casi nada, "incluso en terrenos mejorados" y aunque sean "rocas cubiertas dos veces al día por la marea, cuyo producto nunca puede aumentar por el esfuerzo humano” (ibíd., 
162). Por ello Smith definió la renta como un "precio de monopolio" que se paga por el derecho a usar la parcela que está disponible para el agricultor. Como consecuencia de esa distribución más o menos duradera de los DP de la tierra de finales del siglo XVIII, Smith y los clásicos consideraron que la renta era parte del excedente, y no del costo de producción: "los salarios y la ganancia son causas del precio; la renta es un efecto" (ibíd., 163). Los precios son altos cuando los salarios o las ganancias son altos; la renta es alta solo si los precios son altos. La fertilidad de la tierra y su distancia al mercado son determinantes reales pero secundarios del nivel de renta.

La teoría coherente de la renta diferencial de Ricardo no cambia el hecho de que la renta es el "resultado de la apropiación de la tierra" $(1821,67)$, que se paga al terrateniente "por el uso de los poderes originales e indestructibles del suelo” (ibíd.). Ricardo fue aún más crítico del papel de los terratenientes y explicó su derecho a recibir una renta por la escasez de tierras fértiles y su distancia a las ciudades. Si la tierra fuese ilimitada y tuviese la misma productividad, nadie podría pedir una renta, así como nadie jamás ha pensado en pedir una renta por el derecho a "usar el aire y el agua de los ríos en la producción de mercancías” (ibíd., 69). A medida que la población aumenta y la demanda de alimentos se incrementa, se cultivan más tierras más distantes y menos fértiles, y las tierras existentes se cultivan más intensivamente. En ambos casos, los terratenientes, que se han apropiado de todas las tierras fértiles, piden una renta más alta para permitir que los agricultores sigan cultivando sus campos. La acción combinada de la ley de población y de la ley de rendimientos decrecientes predice un futuro sombrío del capitalismo. La lucha de Ricardo contra la aristocracia terrateniente fue ante todo un alegato para que las clases industriosas aumentaran su productividad.

Senior, que escribió a finales de la primera etapa de la industrialización en Gran Bretaña, empleó el término "agentes naturales" para describir los poderes productivos de la naturaleza, incluidos "el océano, la atmósfera, la luz y el calor" $(1836,58)$. Deploró el uso de la palabra "tierra", al que llamó "sinécdoque inconveniente", aunque subrayó que la tierra es "el más importante de aquellos [agentes] susceptibles de apropiación" (ibíd.). Es significativo que Senior subrayara que el rasgo decisivo del derecho a recibir una renta de un agente natural es que se puede apropiar. También reconoció que la tierra "no es el único agente natural del que es posible apropiarse" (ibíd., 91). Dio igual importancia al "simple conocimiento de las operaciones de la naturaleza, en la medida en que el uso de ese conocimiento puede ser 
limitado por el secreto o por la ley"(ibíd.). Esta es la segunda vez que alguien trata el tema de las patentes industriales y de los derechos de propiedad que se derivan de su protección legal (ver Smith, 1763, 59, 116). Según Senior, "en el lenguaje comercial, el pago que hace un fabricante al titular de la patente por el privilegio de usar el proceso patentado se suele llamar renta" (ibíd., cursivas del original). Como él explicó, así como un terrateniente arrienda su tierra a un agricultor y tiene el derecho de pedir parte del excedente, el innovador vende su descubrimiento a un fabricante y recibe parte de su ganancia. En ambos casos, continúa Senior, "la renta se obtiene sin ningún sacrificio". Una vez se reconoce que alguien es propietario legal de un agente natural, tiene derecho a recibir un ingreso por permitir que otros utilicen ese agente.

John Stuart Mill añadió muy poco a la teoría de la renta, pero avanzó mucho en los asuntos políticos de la propiedad de la tierra y de la reforma institucional. Adoptó la idea de Smith de la renta como "el efecto de un monopolio" $(1973,422)$, respaldó la teoría de la renta diferencial de Ricardo para explicar su formación (ibíd., 425) y aceptó las reservas de Senior sobre el derecho de los terratenientes al excedente agrícola: el propietario de tierras es "la persona que, por los arreglos de la sociedad, posee poder exclusivo sobre algún agente natural" (ibíd., 422). No obstante, Mill tuvo opiniones políticas mucho más drásticas; como activista de los "radicales filosóficos" defendió el programa utilitarista de reformas institucionales de Bentham. Publicó su principal tratado económico en el tumultuoso año de 1848, en el que dedicó muchos capítulos al problema social de la propiedad, que revisó severamente en la siguiente edición por influencia de Harriet Taylor, y abrió así un diálogo con comunistas y fourieristas:

Por consiguiente, si se tuviese que elegir entre el comunismo, con todos sus azares, y el estado actual de la sociedad, con todos sus sufrimientos e injusticias [...] si esto o el comunismo fuese la alternativa, todas las dificultades, grandes o pequeñas, del comunismo no serían más que polvo en el platillo de una balanza (ibíd., 208).

Por supuesto, Mill no se oponía a la propiedad privada en principio. Pero creía firmemente que la propiedad de la tierra solo se justificaba económicamente si se usaba apropiadamente como medio de producción: "ningún hombre hizo la tierra. Es la herencia original de toda la especie. Su apropiación es una cuestión de conveniencia general. Cuando la propiedad privada no es conveniente es injusta"(ibíd., 233).

Sobre esa base, hizo un exhaustivo estudio sociológico de los diferentes modos de distribución de los DP prevalecientes en Europa y sugirió muchas reformas de la propiedad de la tierra para revelar las 
fuentes de su productividad. Después de examinar rápidamente (en cuatro páginas) el sistema capitalista de distribución entre trabajadores, capitalistas y terratenientes, estudió (en cinco capítulos de más de 90 páginas) otros arreglos institucionales de los DP. Primero, el sistema campesino, donde los productores agrícolas eran a la vez propietarios y ellos mismos cultivaban su propio campo. En ese sistema, los incentivos para trabajar y acumular difieren de los del modo de producción capitalista y la pequeña escala de producción no solo es benéfica para la productividad sino para el progreso social en general. Segundo, el sistema de "aparcería”, donde el producto se divide entre terratenientes y trabajadores agrícolas que viven en la tierra y pagan al propietario cierta parte de la producción, conforme a la costumbre establecida en la región. Por último, el sistema de "arrendamiento", mucho menos industrioso, bien sea porque las propiedades eran muy pequeñas o porque la propiedad estaba demasiado dividida. La idea básica de su proyecto de reformas institucionales era crear una nueva organización institucional de derechos de propiedad que aumentara la capacidad productiva de la tierra para la mayor felicidad social: "Una organización excitante es precisamente aquella en la que, mediante motivaciones adecuadas, es más fácil alentar el espíritu de esfuerzo vigoroso" (Mill, 1973, 324).

La distribución inglesa de los DP de la tierra también se debía reformar. La primogenitura en la propiedad de la tierra es el ejemplo más característico donde por tradición prevalecieron normas legales que no siguen los principios de eficiencia o justicia: "El propietario legal de un gran dominio no es necesariamente el poseedor 'bona fide' de todo el ingreso que produce" (ibíd., 894). Mill señala que a pesar de los efectos positivos sobre la productividad de la tierra, debido a la escala de la hacienda, esta costumbre social suele llevar a un "gasto imprudente del propietario”. Defendió la abolición de la primogenitura y la libre disposición de tierras a través del mercado: "el mejor sistema de propiedad de la tierra es aquel en el cual esta es objeto de comercio con la mayor libertad posible" (ibíd., 896). Por ello sugirió que la trayectoria del desarrollo económico se debía orientar en una dirección más eficiente. Distinguió el derecho a heredar del "derecho a legar". El punto esencial era de nuevo la protección del bien común. Pues "la propiedad es solo un medio para un fin, no el fin en sí mismo" (ibíd., 226). Según Mill, el único argumento válido en favor de la propiedad de la tierra es el uso económicamente eficiente; "en tanto el propietario de la tierra es al mismo tiempo el que la mejor. Cuando en un país, y hablando en general, el propietario deja de ser 
el que la mejora, la economía política no puede defender la propiedad de la tierra, tal como esté establecida" (ibíd., 231). En ese sentido, es inaceptable ocupar un pedazo de tierra sin mejorar su productividad en el largo plazo. Mill fue el último de una larga serie de pensadores de tradición liberal que distinguió entre el derecho de una persona a la tierra per se y el derecho a recibir una compensación por su uso productivo. Y así debe ser tratado por "la política del Estado" (ibíd., 233). En conclusión, "en el caso de la tierra no se debe permitir ningún derecho exclusivo a ningún individuo si no se puede demostrar que ese derecho es claramente beneficioso"(ibíd., 235). Además, Mill aprovechó esa oportunidad para mostrar una temprana preocupación ambiental: "La especie en general aún retiene, de su derecho original al suelo del planeta que habita, todo aquello que es compatible con los propósitos para los cuales se ha desprendido del resto" (ibíd.). Como señaló Spash $(1995,290)$, los economistas políticos reconocieron los límites sociales del crecimiento debido a su visión más amplia de la relación entre el hombre y la naturaleza.

\section{CONCLUSIÓN}

¿Cuál es el significado de la excursión histórica anterior? ¿Es valioso el pensamiento clásico para el debate actual sobre DP? La respuesta es innegablemente positiva, por tres razones. Primera, la idea de que los DP solo existen cuando los demás consienten en que su titular actúe de modo particular está arraigada en la tradición clásica, y esto es hoy reconocido en la literatura pertinente (Furubotn y Richter, 1998, 127; Merrill y Smith, 2001, 362). Sin duda, la idea de que las externalidades debían ser internalizadas para que surgieran nuevos DP estaba ausente en los textos clásicos. Pero reconocían que la existencia de nuevos DP es en esencia un resultado del arreglo social entre los miembros de una sociedad o grupo social particular. Salvo que para Smith y los clásicos el fundamento auténtico de toda propiedad era el trabajo, y esta posición era analítica y polémica, contra la aristocracia de la tierra entonces gobernante.

Segunda, la idea de la protección legal era muy importante para los economistas políticos clásicos y, además, reconocida como una característica de una sociedad civilizada. El asunto de los DP era inseparable de su protección por la ley y nunca se equiparó a la simple posesión de un bien o de un recurso, como suele suceder en el análisis moderno de los DP. Es cierto que el estatus de la propiedad evolucionó notablemente desde Smith hasta Mill y que perdió gradualmente su carácter sagrado para volverse socialmente condicionado. Sin embar- 
go, los DP estaban ligados firme y permanentemente a los derechos legales y a su protección. En pocas palabras, los clásicos creían que no podía existir un derecho de propiedad sin hacerlo cumplir legalmente.

Tercera, los economistas clásicos también consideraban la eficiencia de la asignación de los DP, pero sobre una base totalmente diferente, debido a que les era ajeno el concepto de maximización. Lo que era eficiente para ellos estaba determinado principalmente desde el punto de vista social. El asunto de la propiedad se discutía continuamente como parte del tema más importante de la justicia social. Quizá la lección más importante de los clásicos al debate actual sea que amplían los términos estrechos de la optimalidad de Pareto y promueven el punto de vista de la comunidad. Después de todo, esa fue la idea original de la teoría del costo social de Coase: "en el diseño y la elección de diferentes arreglos sociales debemos tener en cuenta el efecto total" $(1960,44)$. Es sorprendente que esta idea también refleje el imperativo de Mill: "las leyes y los arreglos sociales deberían poner la felicidad, o [...] el interés de cada individuo, en la mayor armonía posible con el interés del conjunto" $(1861,218)$.

\section{REFERENCIAS BIBLIOGRÁFICAS}

1. Ackroyd, P. "Greek lessons for property right arrangements: Justice and nature protection", American Journal of Economics and Sociology 51, 1992, pp. 19-26.

2. Alchian, A. "Private property and the relative cost of tenure", D. Bradley, ed., The public stake in union power, Charlottesville, University of Virginia Press, 1959.

3. Alchian, A. y H. Demsetz. "Production, information costs, and economic organization", American Economic Review 62, 5, 1972, pp. 777-795.

4. Alchian, A. y H. Demsetz. "The property rights paradigm", Journal of Economic History 33, 1, 1973, pp. 16-27.

5. Alchian, A. "Property rights", John Eatwell et al., eds., The Nerw Palgrave Dictionary of Political Economy, vol. 3, Londres, MacMillan, 1987.

6. Aspromourgos, T. The science of wealth. Adam Smith and the framing of political economy, Londres, Routledge, 2009.

7. Barzel, Y. Economic analysis of property rights [1989], 2. ${ }^{a}$ ed., Cambridge, Cambridge University Press, 1997.

8. Becker, L. C. Property rights. Philosophical foundations [1977], reimpresión, Londres, Routledge, 2014.

9. Coase, R. "The problem of social cost", Journal of Law E Economics 3, 1960, pp. 1-44.

10. Commons, J. R. Institutional economics. Its place in political economy [1934], reimpresión, New Brunswick, Transaction Publishers, 1990.

11. Demsetz, H. "Aspects of property rights", Journal of Law E Economics 9, 1966, pp. 61-70. 
12. Demsetz, H. “Toward a theory of property rights", American Economic Review 57, 2, 1967, pp. 347-359.

13. Demsetz, H. "Dogs and tails in the economic development story", C. Menard, ed., Institutions, contracts and organizations, Cheltenham, E. Elgar, 2000.

14. Furubotn, E. G. y S. Pejovich. "Property rights and economic theory: A survey of recent literature", Journal of Economic Literature 10, 4, 1972, pp. 1137-1162.

15. Furubotn, E. G. y R. Richter. Institutions and economic theory [1998], 2. ${ }^{a}$ ed., Ann Arbor, University of Michigan Press, 2005.

16. Gordon, S. The history and philosophy of social science, Londres, Routledge, 1991.

17. Hobbes, T. Leviathan [1651], Londres, John Bohn, 1839.

18. Hodgson, G. M. How economics forgot history, Londres, Routledge, 2001.

19. Hodgson, G. M. "Much of the 'economics of property rights' devalues property and legal rights", Journal of Institutional Economics 11, 4, 2015, pp. 683-709.

20. Holcombe, R. “The economic theory of rights", Journal of Institutional Economics 10, 3, 2014, pp. 471-491.

21. Hume, D. An essay on buman nature [1739], Londres, Penguin, 1969.

22. Locke, J. Two treatises of government [1689], Londres, A. Millar et al., 1764.

23. Merrill, T. W. y H. E. Smith. "What happened to property in law and economics?", Yale Law Journal 111, 2, 2001, pp. 357-398.

24. Mill, J. S. Principles of political economy with some of their applications to social philosophy [1848], Nueva York, A. Kelley, 1973.

25. Mill, J. S. "Utilitarianism" [1861], J. M. Robson, ed., Collected works, vol. X, Toronto, University of Toronto Press, 1969.

26. Milonakis, D. y B. Fine. From political economy to economics, Londres, Routledge, 2009.

27. North, D. C. Institutions, institutional change and economic performance, Cambridge, Cambridge University Press, 1990.

28. Randall, A. "Property institutions and economic behavior", Journal of Economic Issues 12, 1, 1978, pp. 1-21.

29. Ricardo, D. Principles of political economy and taxation [1817, 3. ${ }^{a}$ ed., 1821], Sraffa, ed., The works and correspondence of David Ricardo, vol. I, Cambridge, Cambridge University Press, 1951.

30. Samuels, W. J. "Theories of property", Journal of Economic Issues 33, 1, 1999, pp. 183-188.

31. Schumpeter, J. A. History of economic analysis, Londres, Allen and Unwin, 1954.

32. Senior, N. W. An outline of the science of political economy [1836], Nueva York, A. M. Kelley, 1965.

33. Shleifer, A. "Establishing property rights", Proceedings of the World Bank Annual Conference in Development Economics 1994, marzo de 1995, pp. 93-116.

34. Smith, A. Lectures on Jurisprudence [1766], R. Meek, D. Raphael y G. Stein, eds., The Glasgow edition of the works and correspondence of Adam Smith, vol. V, Indianapolis, Liberty Fund, 1982. 
35. Smith, A. An inquiry into the nature and causes of the wealth of nations [1776], Chicago, University of Chicago Press, 1976.

36. Spash, C. L. "The political economy of nature", Review of Political Economy 7, 3, 1995, pp. 279-293.

37. Young, J. “The Humean foundations of Adam Smith's theory of property", Journal of the History of Economic Thought 30, 1, 2008, pp. 49-64.

38. Williamson, O. E. The economic institutions of capitalism, Nueva York, The Free Press, 1985. 